\title{
Efficacy of auditory training in elderly subjects
}

\author{
Aline Albuquerque Morais*, Caroline Nunes Rocha-Muniz and Eliane Schochat \\ Auditory Processing Laboratory, Department of Physical Therapy, Speech Therapy and Occupational Therapy, University of \\ São Paulo, São Paulo, Brazil
}

Auditory training (AT) has been used for auditory rehabilitation in elderly individuals and is an effective tool for optimizing speech processing in this population. However, it is necessary to distinguish training-related improvements from placebo and test-retest effects. Thus, we investigated the efficacy of short-term AT [acoustically controlled auditory training (ACAT)] in elderly subjects through behavioral measures and P300. Sixteen elderly individuals with auditory processing disorder (APD) received an initial evaluation (evaluation 1 - E1) consisting of behavioral and electrophysiological tests (P300 evoked by tone burst and speech sounds) to evaluate their auditory processing. The individuals were divided into two groups. The Active Control Group $(n=8)$ underwent placebo training. The Passive Control Group $(n=8)$ did not receive any intervention. After 12 weeks, the subjects were revaluated (evaluation 2 - E2). Then, all of the subjects underwent ACAT. Following another 12 weeks (eight training sessions), they underwent the final evaluation (evaluation 3 - E3). There was no significant difference between $\mathrm{E} 1$ and $\mathrm{E} 2$ in the behavioral test $[F(9.6)=0.06, p=0.92, \lambda$ de Wilks $=0.65)]$ or P300 $[F(8.7)=2.11, p=0.17, \lambda$ de Wilks $=0.29]$ (discarding the presence of placebo effects

OPEN ACCESS

Edited by:

P. Hemachandra Reddy,

Texas Tech University, USA

Reviewed by:

Ramesh Kandimalla, Texas Tech University, USA Archana Mukhopadhyay,

University of Kansas, USA

*Correspondence: Aline Albuquerque Morais, 51, Cipotânea, University of São Paulo, Butantã, 05360-160 São

Paulo, SP-05360-160, Brazil aline.fonoaudio@gmail.com

Received: 04 February 2015 Accepted: 26 April 2015 Published: 18 May 2015

Citation:

Morais AA, Rocha-Muniz CN and Schochat E (2015) Efficacy of auditory

training in elderly subjects.

Front. Aging Neurosci. 7:78. doi: 10.3389/fnagi.2015.00078 and test-retest). A significant improvement was observed between the pre- and postACAT conditions (E2 and E3) for all auditory skills according to the behavioral methods $[F(4.27)=0.18, p=0.94, \lambda$ de Wilks $=0.97]$. However, the same result was not observed for P300 in any condition. There was no significant difference between P300 stimuli. The ACAT improved the behavioral performance of the elderly for all auditory skills and was an effective method for hearing rehabilitation.

Keywords: auditory perception, auditory processing disorder, auditory training, elderly, speech comprehension, aging, neuroplasticity, P300 event-related potential

\section{Introduction}

The structural and functional changes in the auditory system due to aging can limit speech comprehension during difficult listening situations in elderly people (Corso, 1977; Jerger et al., 1989; Willott, 1991; Chisolm et al., 2003; Gates and Mills, 2005). Previous studies have demonstrated poor performance of elderly people compared with young people during different auditory tasks, including temporal processing, listening in noisy environments, and dichotic listening, indicating that the difficulty in understanding speech among elderly people may be associated with auditory processing disorder (APD) (Dubno et al., 1984; Welsh et al., 1985; Jerger et al., 1989; Cooper and Gates, 1991; Snell, 1997; Phillips et al., 2000; Bellis and Wilber, 2001; Pichora-Fuller and Souza, 2003; Gates and Mills, 2005; Martin and Jerger, 2005; Kraus and Anderson, 2013). Executive functions, such as short-term memory, attention, inhibition, and decision-making, are also essential for understanding speech (Humes, 1996; Pichora-Fuller, 2003). Therefore, auditory rehabilitation 
in elderly people should include actions to minimize peripheral hearing losses and central auditory and executive skills.

Previous studies on auditory training (AT) have demonstrated favorable results in auditory and cognitive perception among elderly people (consequently improving their social participation and quality of life) (Pichora-Fuller and Souza, 2003; Smith et al., 2009; Anderson et al., 2013a,b; Ferguson et al., 2014). AT is based on the plasticity of the central nervous system (Chermak and Musiek, 2002). Previously reported methods have used different tasks, such as more sensory or more cognitive methods; methods performed in a soundproof booth; utilizing specific software programs; methods performed in the home; and different frequencies and durations. Despite the heterogeneity of these methods, AT is generally an effective tool for the auditory rehabilitation in adults (Sweetow and Palmer, 2005; Pichora-Fuller and Levitt, 2012; Henshaw and Ferguson, 2013).

Although AT induces improvements in auditory processing, the effects of short-term training on the aging auditory nervous system remain unknown. Furthermore, according to Ferguson et al. (2014), it is not entirely clear how this intervention can provide real improvements in auditory skills (despite the large increase in the number of products and studies on AT). According to these authors, few studies have used untrained control groups and/or groups undergoing placebo training. The lack of controls may lead to ambiguous data interpretation. Placebo and test-retest effects cannot be ignored. Therefore, it is essential that interventional studies involving AT consider the possibility of these effects when analyzing the results.

Both behavioral and electrophysiological tests of auditory processing have been widely used to monitor auditory interventions. Significant changes in bioelectrical activity within the auditory system are observed after AT (Jirsa, 1992; Kraus et al., 1995; Tremblay et al., 1997, 2001).

P300 is a long latency potential that occurs approximately $300 \mathrm{~ms}$ after a stimulus presentation. It can be elicited by the oddball paradigm, which involves the detection and discrimination of a rare stimulus amid a series of frequent stimuli. P300 can be influenced by higher cognitive functions, including attention and memory, and originates in the primary and secondary areas of the cortex. However, the exact elicitors are unknown (McPherson, 1996; Linden et al., 1999; Musiek and Lee, 2001; Schochat, 2003; Linden, 2005; Polich, 2007). Therefore, this study was motivated by the need to investigate the effects of shortterm training [termed acoustically controlled auditory training (ACAT)] on the aging auditory system using untrained control groups and/or training in placebo groups. This study investigated the effectiveness of ACAT in the elderly through behavioral measures of auditory processing and P300 and controlled for placebo and test-retest effects.

We hypothesized that short-term AT (i.e., ACAT) would generate neurophysiological changes leading to improvements in auditory processing, which is damaged by the degenerative processes of aging. We expected that AT would improve the behavioral performance. We also expected that it would induce earlier P300 peak latencies and increase P300 amplitude at post-test compared to pre-test in the auditory intervention condition alone. Moreover, to assess the effectiveness of ACAT, we investigated the occurrence of test-retest and placebo effects in the study population. Thus, the results can be attributed to ACAT and not the impression that the treatment exerts (positive patient outlooks) or the possibility of learning during the test reapplication.

\section{Materials and Methods}

\section{Subjects}

The present study was approved by the Research Ethics Committee of the Medical School of the Universidade de São Paulo USP (protocol number: 382/12), and all subjects signed informed consent forms. The subjects were recruited after an analysis of the medical records in a longitudinal study of elderly people conducted at the Department of Physical Therapy, Speech Therapy, and Occupational Therapy at the Medical School of USP in which language, hearing, cognition, and functional capacity were assessed in the elderly volunteers between 2010 and 2013.

The study included 16 subjects ( 14 women and 2 men) aged 60-78 years with hearing thresholds of up to $40 \mathrm{~dB}$ horizontal line (HL) (at 500, 1000, and $2000 \mathrm{~Hz}$ ); symmetrical hearing configuration; the presence of a $\mathrm{V}$ wave evoked with click stimuli during the auditory brainstem response (ABR) (difference of up to $0.2 \mathrm{~ms}$ between the ears); and normal scores on the Brazilian version of the Mini-Mental State Examination (MMSE) (Folstein et al., 1975; Brucki et al., 2003) and the Geriatric Depressive Scale (GDS) (Yesavage et al., 1983; Almeida and Almeida, 1999).

Convenience sampling was performed, and more females volunteered to participate in this study. All the subjects complained of decreased speech comprehension and poor performance during at least two auditory skills. None of the patients had a history of psychiatric and/or neurological disorders, used hearing aids, or had previously undergone AT.

\section{Procedures}

The subjects performed an initial assessment (E1) consisting of behavioral and electrophysiological tests and were randomly assigned to two groups. The Passive Control Group (PCG) was composed of eight subjects who did not engage in any activity for 12 weeks and then performed a reevaluation (E2). The Active Control Group (ACG) was composed of eight subjects who participated in a weekly activity (placebo training based on the guidelines proposed by Smith et al., 2009). The weekly activity was watching several 45-min documentaries and answering questions about the videos. The period of video watching was 8 weeks. After 4 weeks ( 12 weeks after E1), the subjects performed a reevaluation (E2). After E2, all subjects $(N=16)$ received true AT for 8 weeks, and, 4 weeks later, they performed the final evaluation (E3).

Figure 1 presents all the stages of the study. The details of the evaluations and AT are described below.

\section{Behavioral Assessments}

Four different auditory skills were evaluated. Auditory close and dichotic listening to linguistic sounds were evaluated using the Speech-in-Noise and Dichotic Digit tests, respectively, in their adapted Brazilian Portuguese versions (Pereira and Schochat, 2011). Temporal ordering and resolution skills were evaluated using the Pitch Pattern Sequence (Musiek, 1994) and Gap-inNoise test (Musiek et al., 2005), respectively. 


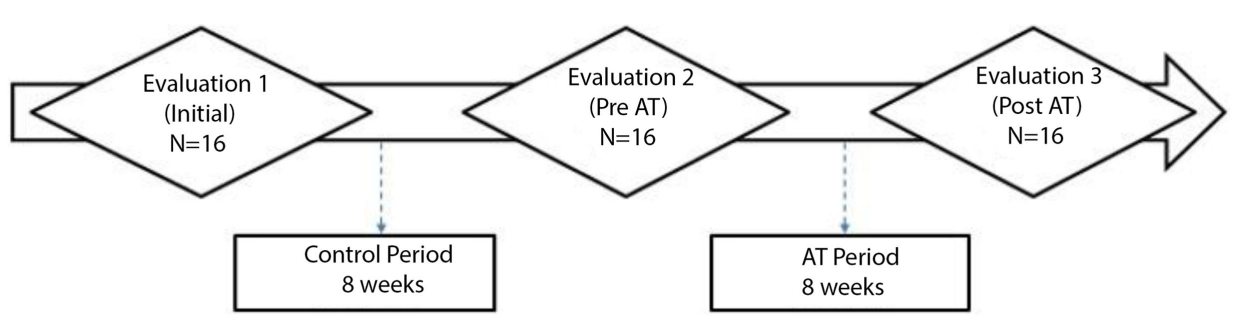

FIGURE 1 | Study design

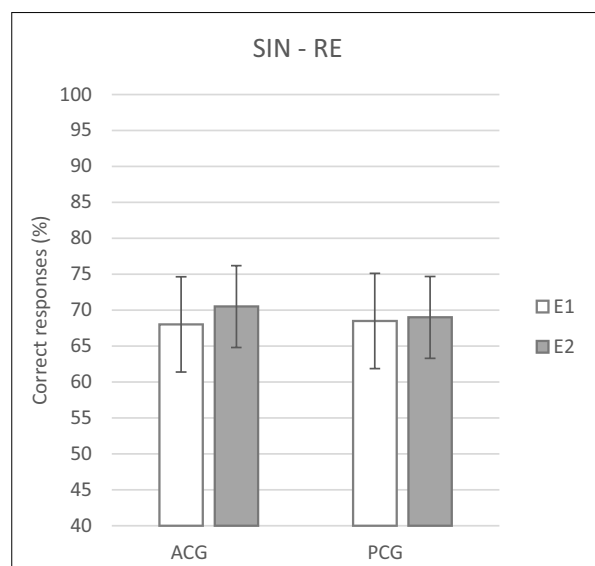

$D D-R E$

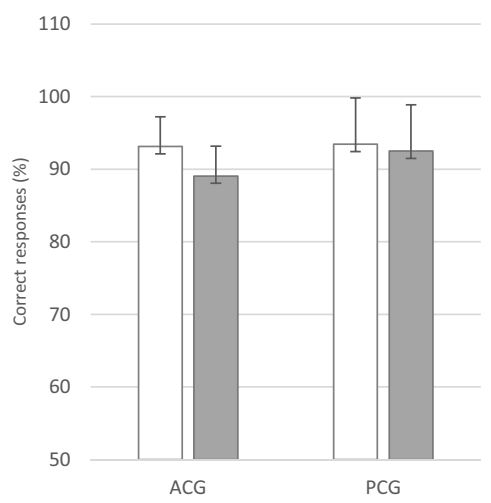

SIN - LE

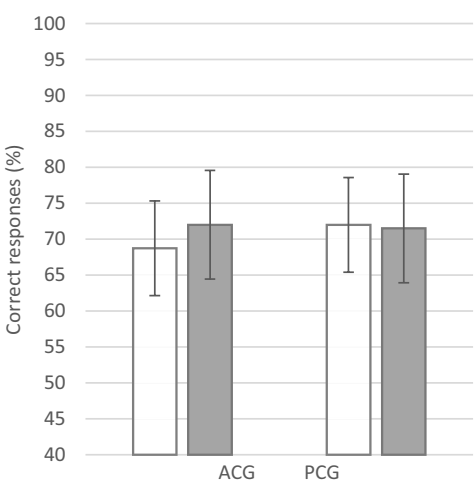

DD - LE

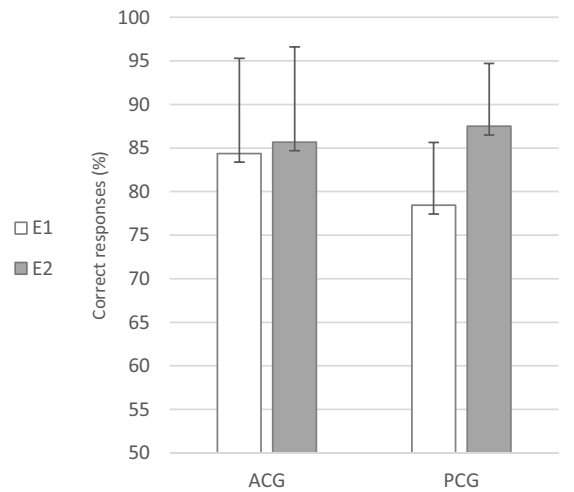

PPS
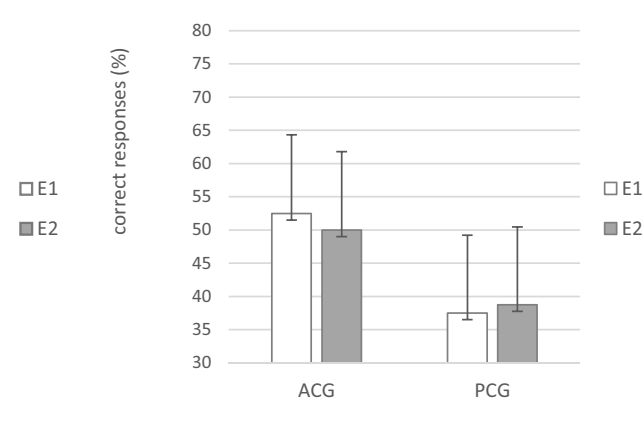

GIN

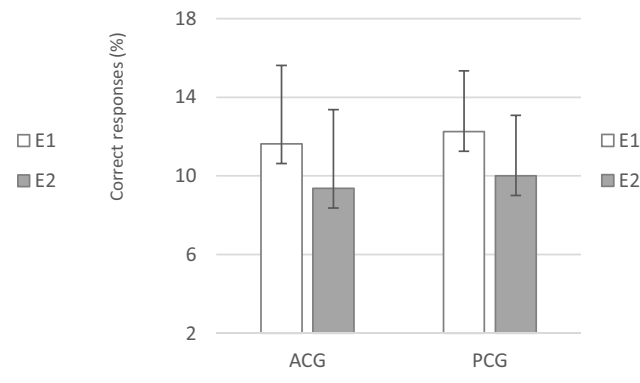

FIGURE 2 | Mean results and error bars indicating the 95\% Cls between E1 and E2 for the behavioral tests. SIN, speech-in-noise; DD, dichotic digits; GIN, gap-in-noise; PPS, pitch pattern sequence; RE, right ear; LE, left ear; E1, evaluation 1 (initial); E2, evaluation 2 (pre-ACAT); ACG, active control group; PCG, passive control group.

\section{Electrophysiologic - P300}

A neuroscan electroencephalographic system (Neuroscan Inc., Herndon, VA, USA) model STIM2 was used to record the P300. The potential was evoked using a tone burst stimulus and a complex speech stimulus. In both situations, the stimuli were presented using insert earphones, and the electrodes were positioned at $\mathrm{Cz}$ (vertex), A1 (left ear), and A2 (right ear). The subjects were instructed to raise their hand when they detected the rare stimulus. Eye movement control was also performed. The parameters were as follows. In total, 300 artifact-free stimuli were used to obtain the potentials ( $85 \%$ were frequent stimuli, and $15 \%$ were rare stimuli). The intensity of the frequent and rare stimuli was $80 \mathrm{~dB}$ sound pressure level (SPL). The presentation rate was one stimulus per second. The analysis window was $600 \mathrm{~ms}$ with alternating polarity; low-pass filter of $30 \mathrm{~Hz}$; high-pass filter of $1 \mathrm{~Hz}$; and $100 \mathrm{~ms}$ duration (plateau of $80 \mathrm{~ms}$ and rise/fall of $10 \mathrm{~ms}$ ). The tone burst was $800 \mathrm{~Hz}$ for the frequent stimulus and $1200 \mathrm{~Hz}$ for the rare stimulus. The synthesized syllables were/da/and/wa/ (Klatt, 1980) for the frequent and rare stimuli, respectively.

Latency (milliseconds) and amplitude (microvolts) values were analyzed in addition to visual analysis of the waves and images generated for both stimuli. P300 was considered to be the highest positive peak between 250 and $450 \mathrm{~ms}$. 


\section{Acoustically Controlled Auditory Training}

The AT used in this study followed the characteristics proposed by Musiek and Schochat (1998). It was conducted in a soundproof booth for 8 weeks with one 50 -min session per week.

The impaired skills detected at E2 were trained, and at the end of each session, 10 min were reserved for guidance regarding communication strategies and the performance of home-based activities (approximately $15 \mathrm{~min}$, three times a week). Each session was planned according to the individual's performance during the previous session while attempting to maintain a success/error rate of approximately 70/30\% (Musiek and Schochat, 1998) and stimulating at least three hearing skills. Verbal and non-verbal stimuli were used. Where possible, both perceptual activities (discrimination of monosyllabic words and compressed disyllabic words, comprehension of sentences in the presence of different types of noise and competitive speech, discrimination and ordering of pure tones, and perception of gaps) and cognitive skills, such as working memory (discrimination of five words among noise and repetition in reverse order of the sequence heard), sensory integration by the aggregation of visual tasks (identification of written sentences), and motor tasks (e.g., pointing to figures corresponding to descriptions heard in the right ear using the left hand) were used in the training. Moreover, we attempted to use a motivating approach, considering the age, preferences, and habits of each individual.

\section{Statistical Analysis}

To compare the average results of the tests in both groups and both ears and the test scores for the three study periods evaluated, multivariate analysis of variance (MANOVA) and MANOVA with repeated measures (repeated-measures MANOVA) were applied, respectively (Dancey and Reidy, 2013). To complement the descriptive analyses, we used confidence intervals (CI) to assess the extent to which the average could vary within a certain confidence probability. The CI established for our data analysis was $95 \%$ with a significance level $(p)$ of $0.05(5 \%)$.

\section{Results}

\section{Placebo and Test-Retest Effects}

The repeated-measures MANOVA indicated no significant differences between the two assessments (E1 and E2) or between the groups (PCG and ACG) for the behavioral $[F(9.6)=0.36, p=0.92$, Wilks $\lambda=0.65]$ or electrophysiological tests $[F(8.7)=2.11, p=0.17$, Wilks $\lambda=0.29]$. The existence of a significant overlap in the 95\% CIs for all the tests in the same period (E1 and E2) and between the groups indicated the absence of a real effect in the $\mathrm{E} 2$ period, i.e., no placebo or test-retest effects occurred. Figures 2 and $\mathbf{3}$ present the CIs for the behavioral and electrophysiological tests, respectively, at assessments E1 and E2.

\section{Effect of ACAT}

Considering the lack of a significant difference between E1 and E2 and between the two groups, the effect of ACAT was assessed after combining the two initial groups into one group $(n=16)$, which was designated the Auditory Training Group

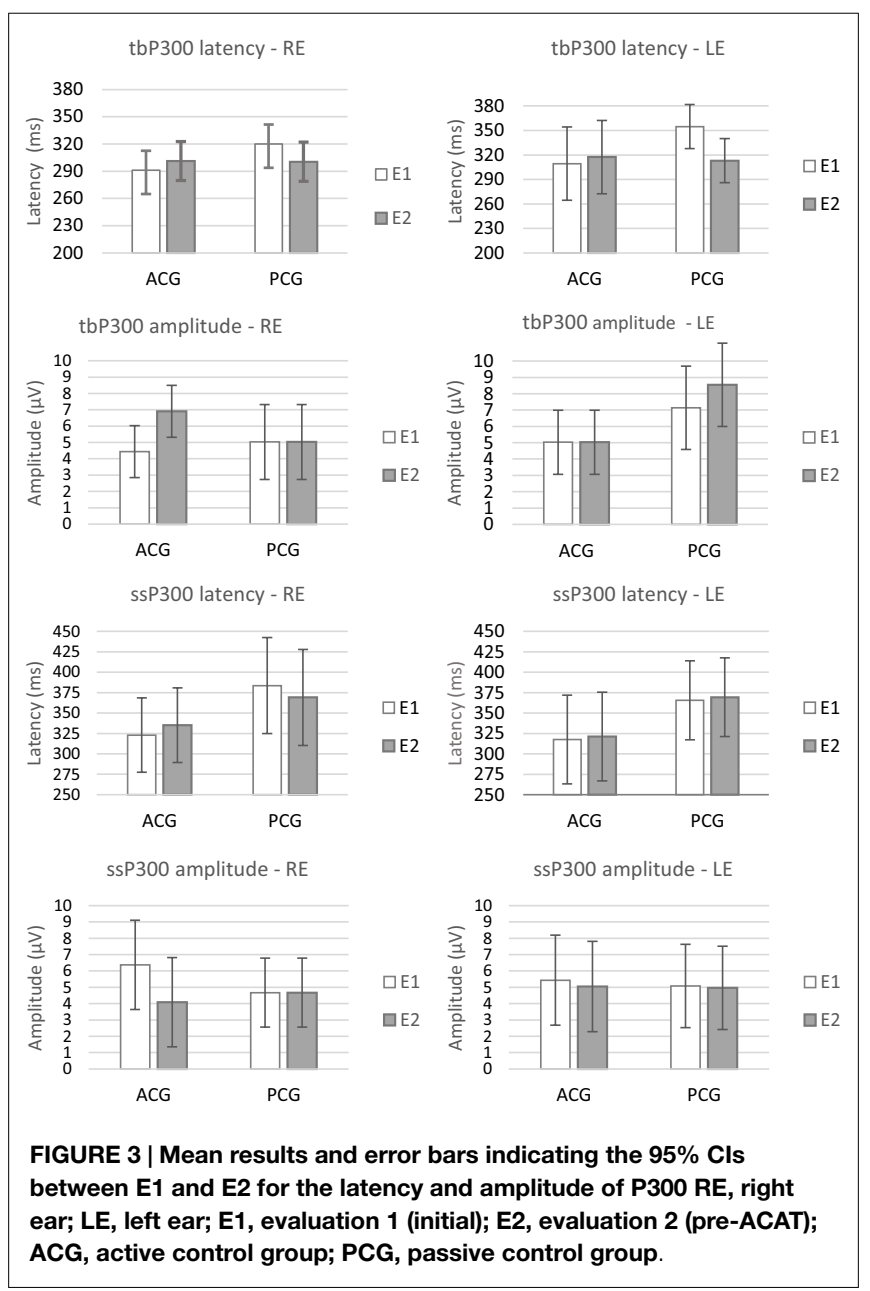

TABLE 1 | Mean values, SD, and $p$-values for the performance of elderly people $(n=16)$ during the behavioral tests at E2 (pre-ACAT) and E3 (postACAT).

\begin{tabular}{lrrrrrrr}
\hline & & \multicolumn{2}{c}{ E2 } & & \multicolumn{2}{c}{ E3 } & p-Value \\
\cline { 3 - 4 } & & Mean & SD & & Mean & SD & \\
\hline GIN (ms) & & 9.69 & 3.94 & & 7.75 & 2.57 & $0.006^{\text {** }}$ \\
PPS (\%) & & 44.38 & 16.01 & 62.81 & 15.16 & $0.001^{\text {** }}$ \\
DD (\%) & RE & 90.78 & 8.30 & 94.23 & 5.37 & $0.08^{\text {a }}$ \\
& LE & 86.59 & 9.22 & 90.78 & 5.61 & $0.008^{\text {** }}$ \\
SIN (\%) & RE & 69.75 & 7.30 & 79.50 & 7.28 & $<0.001^{\text {** }}$ \\
& LE & 71.75 & 9.63 & 81.25 & 8.23 & $0.002^{\text {** }}$
\end{tabular}

SIN, speech-in-noise; DD, dichotic digits; GIN, gap-in-noise; PPS, pitch pattern sequence; $R E$, right ear; $L E$, left ear; E2, evaluation 2 (pre-ACAT); E3, evaluation 3 (post-ACAT); $S D$, standard deviation; ${ }^{*} 0.05$ or less; ${ }^{* *} 0.01$ or less;

atrend toward significance.

(ATG). The repeated-measures MANOVA revealed a multivariate difference between E2 (pre-ACAT) and E3 (post-ACAT) for the behavioral tests $\left[F(9.7)=4.95, p=0.02^{\star}\right.$, partial $\eta^{2}=0.86$, Wilks $\lambda=0.13]$. To assess the relative contribution of each behavioral test to the multivariate differences, univariate analyses were performed (Table 1). Significant differences between E2 and E3 were observed for the following variables: SIN RE $\left(p<0.001^{\star * *}\right)$; 
SIN LE $\left(p=0.002^{\star *}\right) ; \operatorname{DD} \operatorname{LE}\left(p=0.008^{\star *}\right) ; \operatorname{GIN}\left(p=0.006^{\star *}\right)$; and PPS $\left(p<0.001^{\star * *}\right)$. The variable DD was almost significant $\left(p=0.08^{\#}\right)$. Furthermore, we verified that the most difficult task for elderly people was temporal processing, which was reflected by the values obtained in the PPS, compared to other skills measured.

Figure 4 presents the CIs for the behavioral tests at assessments E2 and E3. These results indicate that ACAT improved all of the auditory skills evaluated. The repeated-measures MANOVA indicated no significant differences for the P300 variables (Table 2) with either the tone burst stimulus or the speech-sound stimulus between the periods E2 and E3 $[F(8.8)=0.61, p=0.74$, Wilks $\lambda=0.62]$.

The P300 group averages pre- and post-ACAT for both stimuli are presented in Figure 5. Figure 6 presents the CIs for the electrophysiological tests at E2 and E3. No significant differences were observed between the types of stimuli used for assessing ACAT $[F(4.27)=0.18, p=0.94$, Wilks $\lambda=0.97]$. Although there were no significant differences between the evaluations, it is important to note that in several subjects receiving ACAT, we observed better latencies, amplitudes, and waveform morphologies of the P300 waves (Figure 7).

\section{Discussion}

\section{Placebo and Test-Retest Effects}

The main objective of this study was to evaluate the effectiveness of ACAT in elderly individuals with two or more impaired auditory processing skills. For this purpose, we initially investigated the occurrence of test-retest and placebo effects. No evidence of these effects (test-retest and placebo) was found for any of the tests (behavioral or electrophysiological) evaluated (Figures 2 and 3). This result indicates that the tasks performed during this period did not produce different behaviors from the ones presented initially. This finding confirms the results of previous studies on neuroplasticity, indicating that increases in coordination and synchronization of the neural responses occur only through "learning-driven training" and consequently is "a primary determinant of the feed-forward power of any plastically strengthening cortical process" (Merzenich et al., 2014). This finding indicates that the changes observed after the interventions are attributed exclusively to the proposed ACAT (Anderson et al., 2013a; Ferguson et al., 2014).

Regarding auditory processing abilities, we observed that the most difficult task for elderly people was temporal processing as reflected by the values obtained in the PPS (E2/pre-ACAT). According to Tallal and Newcombe (1978), there is a direct association between temporal acoustic perception and speech perception. Therefore, the temporal-processing deficit due to aging may contribute to the impairment of speech perception. In other words, the accuracy of this coding is impaired by aging and directly affects speech understanding.

Temporal processing difficulties among elderly people have been corroborated by several studies (Gordon-Salant and Fitzgibbons, 1999; Phillips et al., 2000; Parra et al., 2004; Martin and Jerger, 2005; Liporaci and Frota, 2010). In addition, other studies (Bellis and Wilber, 2001; Azzolini and Ferreira, 2010; Hennig et al., 2012) have demonstrated that the performance of elderly people on the same test used in the present study (PPS) was

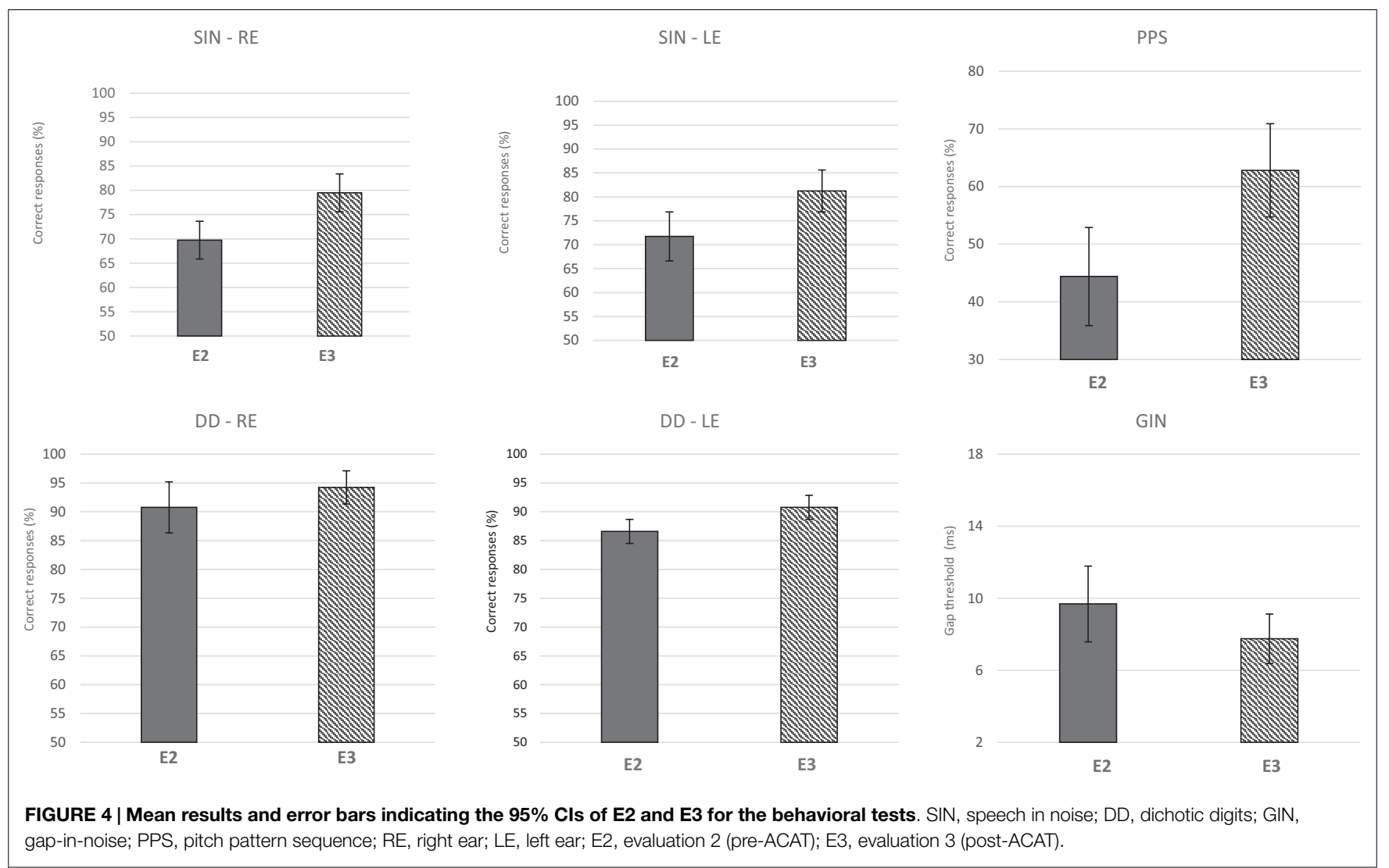


TABLE 2 | Mean values, SDs, and $p$-values for the latency (milliseconds) and amplitude (microvolts) measures of P300 using tone burst and speechsound stimuli in elderly people $(n=16)$ at E2 (pre-ACAT) and E3 (postACAT).

\begin{tabular}{llrrrrr}
\hline & & \multicolumn{2}{c}{ E2 } & & \multicolumn{2}{c}{ E3 } \\
\cline { 7 - 7 } & & Mean & SD & & Mean & SD \\
\hline tbP300 latency & RE & 300.90 & 27.39 & & 292.00 & 27.64 \\
& LE & 315.23 & 34.41 & & 310.01 & 62.05 \\
tbP300 amplitude & RE & 6.21 & 3.00 & & 6.65 & 2.55 \\
& LE & 6.79 & 3.72 & & 7.53 & 2.96 \\
ssP300 latency & RE & 352.10 & 77.07 & & 332.46 & 70.12 \\
& LE & 345.38 & 66.32 & 328.17 & 54.30 \\
ssP300 amplitude & RE & 4.38 & 2.71 & 5.22 & 3.70 \\
& LE & 5.00 & 3.26 & 6.21 & 3.26 \\
p-Value & & & & 0.74 & & \\
\hline
\end{tabular}

tbP300, tone burst P300; sSP300, speech sound P300; RE, right ear; LE, left ear; E2, evaluation 2 (pre-ACAT); E3, evaluation 3 (post-ACAT) SD, standard deviation.

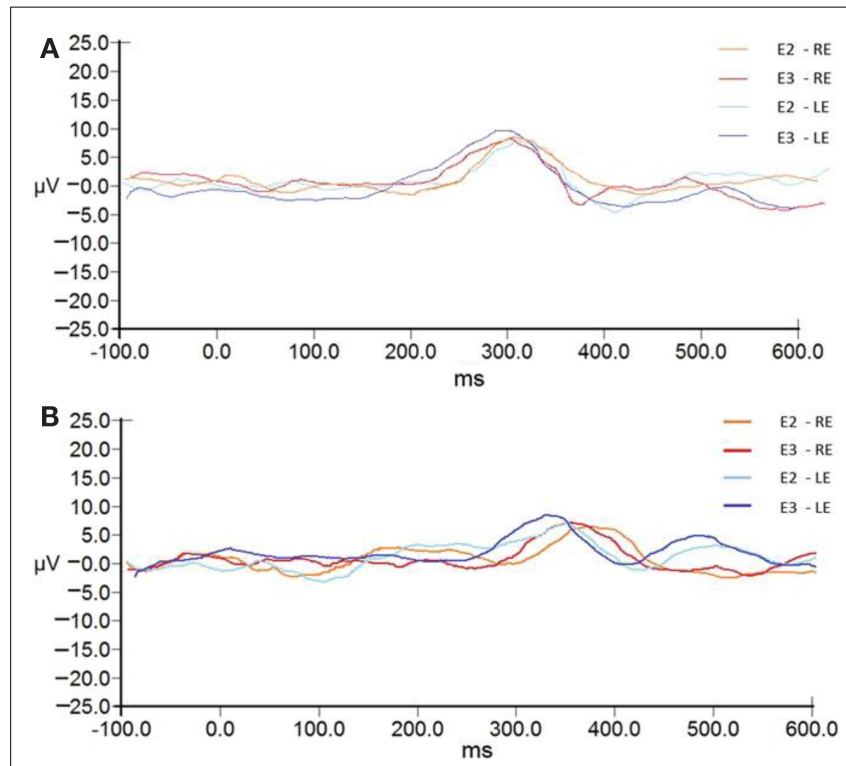

FIGURE 5 | P300 group averages pre- and post-ACAT for both stimuli. (A) presents the waves to tone bursts. (B) presents the waves to the speech stimulus. Note later latencies and lower amplitudes for the stimulation of speech. RE, right ear; LE, left ear; E2, evaluation 2 (pre-AT); E3, evaluation 3 (post-AT).

very similar to the performance of young adults, although the responses were obtained by humming (not naming). One possible explanation is related to the decreased function of the corpus callosum. When this test is performed through the acquisition of a verbal response that requires naming, the auditory information of the tonal pattern is detected and recognized by the right hemisphere and is then conducted (via the corpus callosum) to the left hemisphere. Then, these stimuli are associated with their linguistic representations and the organization of verbal responses (Musiek and Pinheiro, 1987). When the same test is performed by humming, inter-hemispheric transfer via the corpus callosum is not required.
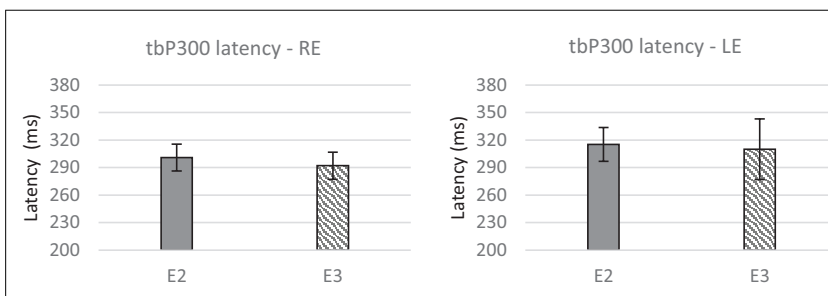

tbP300 amplitude - RE
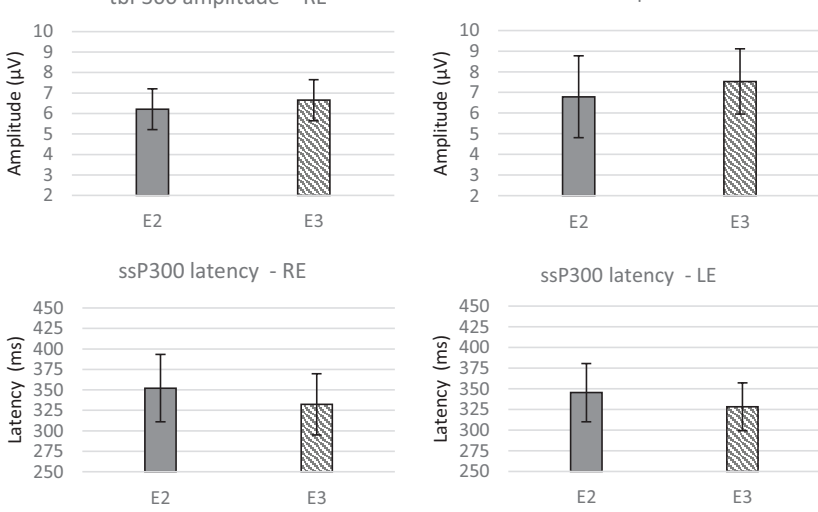

ssP300 amplitude - RE
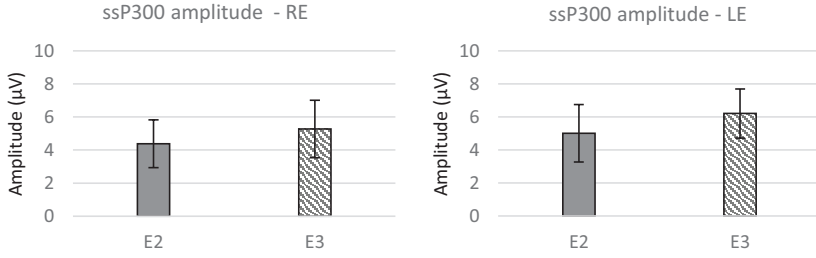

FIGURE 6 | Mean values and error bars indicating the $95 \% \mathrm{Cls}$ between E2 and E3 for the electrophysiological tests. RE, right ear; LE, left ear; E2, evaluation 2 (pre-ACAT); E3, evaluation 3 (post-ACAT).

Other studies using objective techniques, such as functional magnetic resonance imaging (Salat et al., 1997; Silver et al., 1997; Gootjes et al., 2006), have revealed anatomical changes due to aging, including decreased mass in specific regions and decreased fiber myelination in the corpus callosum. Therefore, our findings reinforce the hypothesis that the aging process impairs the function of the corpus callosum.

\section{Effect of Acoustical Controlled Auditory Training}

Specifically, we demonstrated that short-term training-induced neural plasticity in older adults in some aspects of auditory processing. After directed stimulation using ACAT, a significant improvement was observed in all auditory skills, which are observed through behavioral assessment tests (Table 1; Figure 4). These findings are supported by other studies that report the occurrence of neuroplasticity even during conditions of aging (Swain and Richard, 1993; Merzenich and DeCharms, 1996; Kilgard et al., 2001; Weinberger, 2004; Gilbert et al., 2009; Merzenich et al., 2013, 2014). Neuroplasticity is the intrinsic property of the nervous system that allows the development of structural changes in response to experiences and environmental changes (PascualLeone et al., 2005). Therefore, intense auditory stimulation during AT modifies the function of the auditory system leading to positive behavioral changes (Musiek et al., 2002; Fritz et al., 2005; Song et al., 2011). 

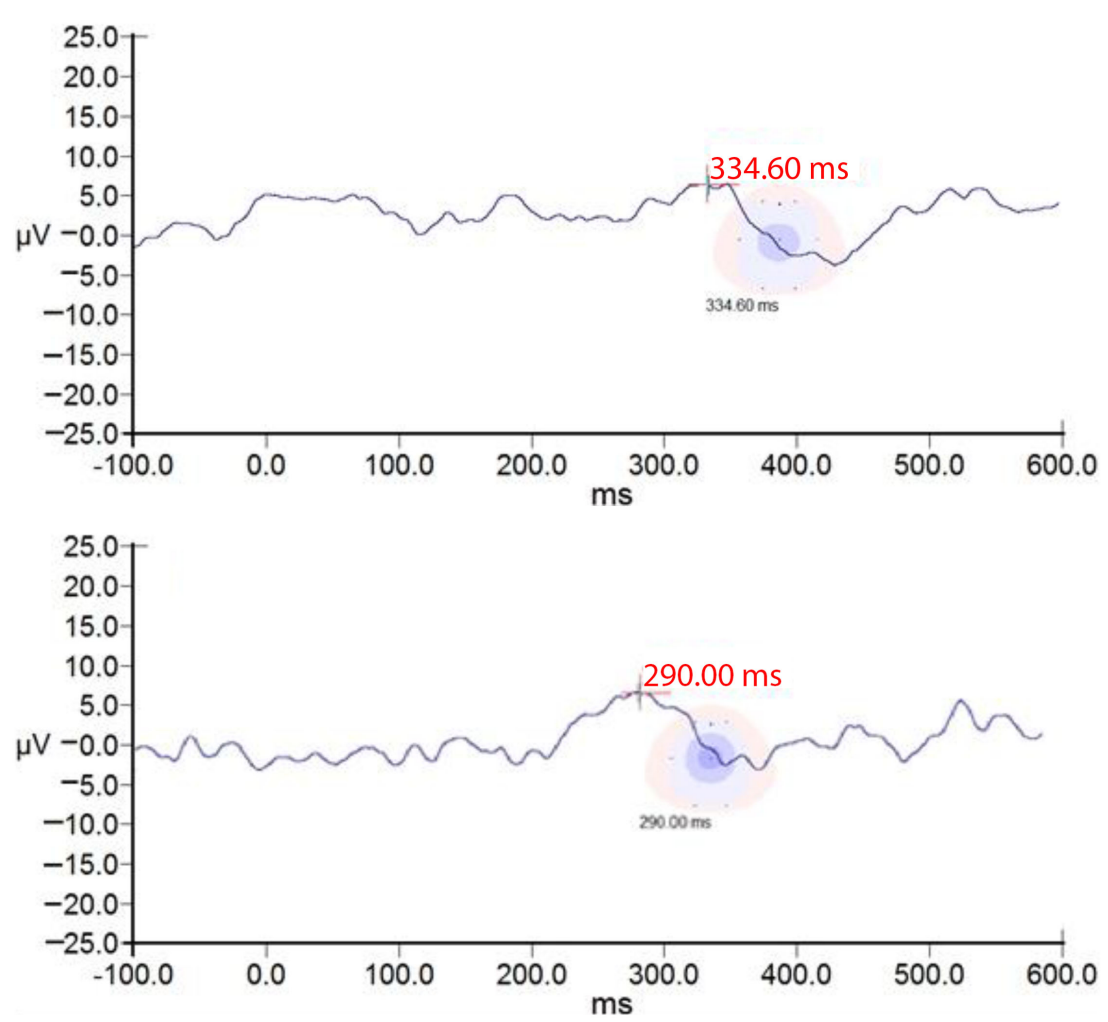

FIGURE 7 | ssP300 RE morphology of one subject at E2 and E3. ssP300 RE of one subject at E2 (A) and E3 (B). Note better latency, morphology of the SSP300 wave after auditory training.

The optimal intensity and duration of AT remain unknown (Molloy et al., 2012). In most studies (Tremblay and Kraus, 2002; Burk et al., 2006; Burk and Humes, 2008; Smith et al., 2009; Anderson et al., 2013a, 2014; Ferguson et al., 2014), the frequency and duration of AT differed from our study and the sessions were performed daily or more than once per week (Anderson and Kraus, 2013). In addition to the intensity, frequency, and duration of AT, previous studies performing AT have also differed in their methods, stimuli, and other variables (home- or lab-based and tone, phoneme, word, or sentence-based training). These differences make comparisons between studies difficult. However, we highlight that the ACAT proposed in our study significantly improved the auditory skills of elderly people even when performing the exercises only once per week for 8 weeks. Despite the promising results described in the present study using behavioral assessments, similar pre- and post-ACAT changes were not achieved with the electrophysiological assessments of P300 with tone burst or speech stimuli (Table 2; Figure 6).

Several studies have demonstrated the effectiveness of AEPs (short, medium, and long latency) to monitor the neurophysiological changes arising from AT using tone burst (Jirsa, 1992; Tremblay and Kraus, 2002; Gil, 2006; Musiek et al., 2007; Alonso and Schochat, 2009) and speech stimuli (Tremblay et al., 2001; Tremblay and Kraus, 2002; Alonso, 2011; Anderson et al., 2013a,b). However, the electrophysiological evaluation of P300 has some peculiarities in relation to other electrophysiological tests. P300 can be influenced by the test parameters, including the type of stimulus, inter-stimulus interval, type of task, cognitive factors (attention and memory), hormonal factors, and other factors (Patterson et al., 1988; Kügler et al., 1993; Polich, 1996; Hirayasu et al., 2000). These parameters may be altered in elderly people. Therefore, we believe that the possible significant effect of the two stimuli used for the P300 potential depends on many other factors in addition to the factors that govern auditory processing.

One of the factors that causes social isolation among elderly people is the well-known complaint that "I hear, but I don't understand." Therefore, ACAT should be considered for the management of communication difficulties in older adults and may mitigate some of the psychosocial sequelae that can exacerbate aging effects, such as depression and social isolation.

Considering the difficulties experienced by the subjects regarding auditory processing and pattern changes during poststimulation auditory processing, we believe that the proposed ACAT can promote changes in behavioral performance in elderly people for all the auditory skills investigated. ACAT was an effective method for auditory rehabilitation in elderly people with APD. Although the present study did not find any evidence of neuroplasticity (P300), we encourage the use of other electrophysiological measures to monitor neurophysiological changes during the aging process. In addition, other studies should evaluate the maintenance of treatment effects over time, including self-assessment and quality of life questionnaires, to confirm the incorporation of these improved auditory skills into daily life.

In conclusion, this study demonstrates that ACAT (short-term training) can improve auditory processing even during the degenerative processes caused by aging. 


\section{References}

Almeida, O. P., and Almeida, S. A. (1999). Confiabilidade da versão brasileira da Escala de Depressão em Geriatria (GDS) versão reduzida. Arq. Neuropsiquiatr. 57, 421-426. doi:10.1590/S0004-282X1999000300013

Alonso, R. (2011). Avaliação eletrofisiológica e comportamental do processamento auditivo (central) e treinamento auditivo em indivíduos idosos. [doutorado]. São Paulo: Universidade de São Paulo.

Alonso, R., and Schochat, E. (2009). The efficacy of formal auditory training in children with (central) auditory processing disorder: behavioral and electrophysiological evaluation. Braz. J. Otorhinolaryngol. 75, 726-732. doi:10.1590/ S1808-86942009000500019

Anderson, S., and Kraus, N. (2013). Auditory training: evidence for neural plasticity in older adults. Perspect. Hear. Hear. Disord. Res. Res. Diagn. 17, 37-57. doi:10. 1044/hhd17.1.37

Anderson, S., White-Schwoch, T., Parbery-Clark, A., and Kraus, N. (2013a). Reversal of age-related neural timing delays with training. Proc. Natl. Acad. Sci. U.S.A. 110, 4357-4362. doi:10.1073/pnas.1213555110

Anderson, S., White-Schwoch, T., Choi, H. J., and Kraus, N. (2013b). Training changes processing of speech cues in older adults with hearing loss. Front. Syst. Neurosci. 7:97. doi:10.3389/fnsys.2013.00097

Anderson, S., White-Schwoch, T., Jae Choi, H., and Kraus, N. (2014). Partial maintenance of auditory-based cognitive training benefits in older adults. Neuropsychologia 62, 286-296. doi:10.1016/j.neuropsychologia.2014.07.034

Azzolini, V. C., and Ferreira, M. (2010). Processamento auditivo temporal em idosos. Arq. Int. Otorrinolaringol. 14, 95-102.

Bellis, T. J., and Wilber, L. A. (2001). Effects of aging and gender on interhemispheric function. J. Speech Lang. Hear. Res. 44, 246-263. doi:10.1682/JRRD.2004.12.0164

Brucki, S., Nitrini, R., Caramelli, P., Bertolucci, P. H., and Okamoto, I. H. (2003). Suggestions for utilization of the mini-mental state examination in Brazil. Arq. Neuropsiquiatr. 61, 777-781. doi:10.1590/S0004-282X2003000500014

Burk, M. H., and Humes, L. E. (2008). Effects of long-term training on aided speech recognition performance in noise in older adults. J. Speech Lang. Hear. Res. 51, 759-771. doi:10.1044/1092-4388(2008/054)

Burk, M. H., Humes, L. E., Amos, N. E., and Strauser, L. E. (2006). Effect of training on word-recognition performance in noise for young normal-hearing and older hearing-impaired listeners. Ear Hear. 27, 263-278. doi:10.1097/01. aud.0000215980.21158.a2

Chermak, G. D., and Musiek, F. E. (2002). Auditory training: principles and approaches for remediating and managing auditory processing disorders. Semin. Hear. 23, 297-308. doi:10.1055/s-2002-35878

Chisolm, T. H., Willott, J., and Lister, J. (2003). The aging auditory system: anatomic and physiologic changes and implications for rehabilitation. Int. J. Audiol. 42, S3-S10. doi:10.3109/14992020309074637

Cooper, J. Jr., and Gates, G. A. (1991). Hearing in the elderly-the Framingham cohort, 1983-1985: part II. Prevalence of central auditory processing disorders. Ear Hear. 12, 304-311. doi:10.1097/00003446-199110000-00002

Corso, J. F. (1977). Presbycusis, hearing aids and aging. Int. J. Audiol. 16, 146-163. doi:10.3109/00206097709071829

Dancey, C. P., and Reidy, J. (2013). Estatística sem matemática para psicologia, 5 Edn. Porto Alegre: Artmed.

Dubno, J. R., Dirks, D. D., and Morgan, D. E. (1984). Effects of age and mild hearing loss on speech recognition in noise. J. Acoust. Soc. Am. 76, 87-96. doi:10.1121/1.391011

Ferguson, M., Henshaw, H., Clark, D., and Moore, D. (2014). Benefits of phoneme discrimination training in a randomized controlled trial of 50-74 year olds with mild hearing loss. Ear Hear. 35, e110-e121. doi:10.1097/AUD. 0000000000000020

Folstein, M. F., Folstein, S. E., and McHugh, P. R. (1975). "Mini-mental state": a practical method for grading the cognitive state of patients for the clinician. J. Psychiatr. Res. 12, 189-198. doi:10.1016/j.heares.2005.01.015

Fritz, J., Elhilali, M., and Shamma, S. (2005). Active listening: task-dependent plasticity of spectrotemporal receptive fields in primary auditory cortex. Hear. Res. 206, 159-176. doi:10.1016/j.heares.2005.01.015

Gates, G. A., and Mills, J. H. (2005). Presbycusis. Lancet 366, 1111-1120. doi:10. 1016/S0140-6736(05)67423-5

Gil, D. (2006). Treinamento auditivo formal em adultos com deficiência auditiva. [tese]. São Paulo: Universidade Federal de São Paulo.
Gilbert, C. D., Li, W., and Piech, V. (2009). Perceptual learning and adult cortical plasticity. J. Physiol. 587(Pt 12), 2743-2751. doi:10.1113/jphysiol.2009.171488

Gootjes, L., Bouma, A., Van Strien, J. W., Schijndel, R. V., Barkhof, F., and Scheltens, P. (2006). Corpus callosum size correlates with asymmetric performance on a dichotic listening task in healthy aging but not in Alzheimer's disease. Neuropsychologia 44, 208-217. doi:10.1016/j.neuropsychologia.2005.05.002

Gordon-Salant, S., and Fitzgibbons, P. J. (1999). Profile of auditory temporal processing in older listeners. J. Speech Lang. Hear. Res. 42, 300-311. doi:10.1044/ jslhr.4202.300

Hennig, T. R., Costa, M. J., Rossi, A. G., and de Moraes, A. B. (2012). Efeitos da reabilitação auditiva na habilidade de ordenação temporal em idosos usuários de próteses auditivas. J. Soc. Bras. Fonoaudiol. 24, 26-33. doi:10.1590/ S2179-64912012000100006

Henshaw, H., and Ferguson, M. A. (2013). Efficacy of individual computer-based auditory training for people with hearing loss: a systematic review of the evidence. PLoS ONE 8:e62836. doi:10.1371/journal.pone.0062836

Hirayasu, Y., Samura, M., Ohta, H., and Ogura, C. (2000). Sex effects on rate of change of P300 latency with age. Neurophysiol. Clin. 111, 187-194. doi:10.1016/ S1388-2457(99)00233-3

Humes, L. E. (1996). Speech understanding in the elderly. J. Am. Acad. Audiol. 7, $161-167$.

Jerger, J., Jerger, S., Oliver, T., and Pirozzolo, F. (1989). Speech understanding in the elderly. Ear Hear. 10, 79-89. doi:10.1097/00003446-198904000-00001

Jirsa, R. E. (1992). The clinical utility of the P3 AERP in children with auditory processing disorders. J. Speech Hear. Res. 35, 903-912. doi:10.1044/jshr.3504.903

Kilgard, M. P., Pandya, P. K., Vazquez, J., Gehi, A., Schreiner, C. E., and Merzenich, M. M. (2001). Sensory input directs spatial and temporal plasticity in primary auditory cortex. J. Neurophysiol. 86, 326-338.

Klatt, D. H. (1980). Software for a cascade/parallel formant synthesizer. J. Acoust. Soc. Am. 67, 971-995. doi:10.1121/1.383940

Kraus, N., and Anderson, S. (2013). The effects of aging on auditory processing. Hear. J. 66, 36. doi:10.1097/01.HJ.0000425774.80002.ea

Kraus, N., McGee, T., Carrell, T. D., King, C., Tremblay, K., and Nicol, T. (1995). Central auditory system plasticity associated with speech discrimination training. J. Cogn. Neurosci. 7, 25-32. doi:10.1162/jocn.1995.7.1.25

Kügler, C. F., Taghavy, A., and Platt, D. (1993). The event-related P300 potential analysis of cognitive human brain aging: a review. Gerontology 39, 280-303. doi:10.1159/000213544

Linden, D. E. (2005). The P300: where in the brain is it produced and what does it tell us? Neuroscientist. 11, 563-576. doi:10.1177/1073858405280524

Linden, D. E., Prvulovic, D., Formisano, E., Völlinger, M., Zanella, F. E., Goebel, R., et al. (1999). The functional neuroanatomy of target detection: an fMRI study of visual and auditory oddball tasks. Cereb. Cortex 9, 815-823. doi:10.1093/cercor/ 9.8.815

Liporaci, F. D., and Frota, S. M. M. C. (2010). Envelhecimento e ordenação temporal auditiva. Rev. CEFAC 12, 741-748. doi:10.1590/S1516-18462010005000078

Martin, J. S., and Jerger, J. F. (2005). Some effects of aging on central auditory processing. J. Rehabil. Res. Dev. 42, 25. doi:10.1682/JRRD.2004.12.0164

McPherson, D. L. (1996). Late Potentials of the Auditory System. San Diego: Singular Publishing Group.

Merzenich, M. M., and DeCharms, R. C. (1996). "Neural representations, experience and change," in The Mindbrain Continuum, eds R. Llinas and P. Churchland (Boston, MA: MIT Press), 61-81.

Merzenich, M. M., Nahum, M., and Van Vleet, T. M. (2013). Neuroplasticity: introduction. Prog. Brain Res. 207, xxi-xxvi. doi:10.1016/B978-0-444-63327-9. 10000- 1

Merzenich, M. M., Van Vleet, T. M., and Nahum, M. (2014). Brain plasticity-based therapeutics. Front. Hum. Neurosci. 8:385. doi:10.3389/fnhum.2014.00385

Molloy, K., Moore, D. R., Sohoglu, E., and Amitay, S. (2012). Less is more: latent learning is maximized by shorter training sessions in auditory perceptual learning. PLoS ONE 7:e36929. doi:10.1371/journal.pone.0036929

Musiek, F., and Pinheiro, M. (1987). Frequency patterns in cochlear, brainstem, and cerebral lesions. Audiology 26, 79-88. doi:10.3109/00206098709078409

Musiek, F. E. (1994). Frequency (pitch) and duration patterns tests. J. Am. Acad. Audiol. 5, 265-268.

Musiek, F. E., Chermak, G. D., and Weihing, J. (2007). "Auditory training," in Handbook of Central Auditory Processing Disorder, Vol. 2. eds F. E. Musiek and G. D. Chermak (San Diego: Plural Publishing), 77-106. 
Musiek, F. E., and Lee, W. W. (2001). "Potenciais auditivos de média e longa latência," in Perspectivas atuais em avaliação auditiva, eds F. E. Musiek and W. W. Lee (São Paulo: Manole), 239-267.

Musiek, F. E., and Schochat, E. (1998). Auditory training and central auditory processing disorders: a case study. Semin. Hear. 19, 357-366. doi:10.1055/ s-0028-1082983

Musiek, F. E., Shinn, J., and Hare, C. (2002). Plasticity, auditory training, and auditory processing disorders. Semin. Hear. 23, 263-276. doi:10.1055/s-2002-35862

Musiek, F. E., Shinn, J. B., Jirsa, R., Bamiou, D.-E., Baran, J. A., and Zaida, E. (2005). GIN (Gaps-In-Noise) test performance in subjects with confirmed central auditory nervous system involvement. Ear Hear. 26, 608-618. doi:10.1097/01.aud. 0000188069.80699 .41

Parra, V. M., Iório, M. C., Mizahi, M. M., and Baraldi, G. S. (2004). Testes de Freqüência e duração em idosos com sensibilidade auditiva normal. Rev. Bras. Otorrinolaringol. 70, 517-523. doi:10.1590/S0034-72992004000400013

Pascual-Leone, A., Amedi, A., Fregni, F., and Merabet, L. B. (2005). The plastic human brain cortex. Annu. Rev. Neurosci. 28, 377-401. doi:10.1146/annurev. neuro.27.070203.144216

Patterson, J. V., Michalewski, H. J., and Starr, A. (1988). Latency variability of the components of auditory event-related potentials to infrequent stimuli in aging, Alzheimer-type dementia, and depression. Electroencephalogr. Clin. Neurophysiol. 71, 450-460. doi:10.1016/0168-5597(88)90049-4

Pereira, L. D., and Schochat, E. (2011). Testes Auditivos Comportamentais Para Avaliação do Processamento Auditivo Central. São Paulo: Pró-Fono. 1-82.

Phillips, S. L., Gordon-Salant, S., Fitzgibbons, P. J., and Yeni-Komshian, G. (2000). Frequency and temporal resolution in elderly listeners with good and poor word recognition. J. Speech Lang. Hear. Res. 43, 217-228. doi:10.1044/jslhr.4301.217

Pichora-Fuller, M. K. (2003). Cognitive aging and auditory information processing. Int. J. Audiol. 42(Suppl. 2), S26-S32. doi:10.3109/14992020309074641

Pichora-Fuller, M. K., and Levitt, H. (2012). Speech comprehension training and auditory and cognitive processing in older adults. Am. J. Audiol. 21, 351-357. doi:10.1044/1059-0889(2012/12-0025)

Pichora-Fuller, M. K., and Souza, P. E. (2003). Effects of aging on auditory processing of speech. Int. J. Audiol. 42, 11-16. doi:10.3109/14992020309074641

Polich, J. (1996). Meta-analysis of P300 normative aging studies. Psychophysiology 33, 334-353. doi:10.1111/j.1469-8986.1996.tb01058.x

Polich, J. (2007). Updating P300: an integrative theory of P3a and P3b. Neurophysiol. Clin. 118, 2128-2148. doi:10.1016/j.clinph.2007.04.019

Salat, D., Ward, A., Kaye, J., and Janowsky, J. (1997). Sex differences in the corpus callosum with aging. Neurobiol. Aging 18, 191-197. doi:10.1016/S0197-4580(97) 00014-6

Schochat, E. (2003). "Respostas de longa latência," in Fonoaudiologia: informação para a formação - procedimentos em audiologia, ed. R. M. M. Carvallo (Rio de Janeiro: Guanabara Koogan), 71-85.

Silver, N., Barker, G., MacManus, D., Tofts, P., and Miller, D. (1997). Magnetisation transfer ratio of normal brain white matter: a normative database spanning four decades of life. J. Neurol. Neurosurg. Psychiatr. 62, 223-228. doi:10.1136/jnnp. 62.3 .223
Smith, G. E., Housen, P., Yaffe, K., Ruff, R., Kennison, R. F., Mahncke, H. W., et al. (2009). A cognitive training program based on principles of brain plasticity: results from the improvement in memory with plasticity-based adaptive cognitive training (IMPACT) study. J. Am. Geriatr. Soc. 57, 594-603. doi:10. $1111 / j .1532-5415.2008 .02167 . x$

Snell, K. B. (1997). Age-related changes in temporal gap detection. J. Acoust. Soc. Am. 101, 2214-2220. doi:10.1121/1.418205

Song, J. H., Skoe, E., Banai, K., and Kraus, N. (2011). Training to improve hearing speech in noise: biological mechanisms. Cereb. Cortex 22, 1180-1190. doi:10. 1093/cercor/bhr196

Swain, R. A., and Richard, F. T. (1993). In search of engramsa. Ann. N. Y. Acad. Sci. 702, 27-39. doi:10.1111/j.1749-6632.1993.tb17240.x

Sweetow, R., and Palmer, C. V. (2005). Efficacy of individual auditory training in adults: a systematic review of the evidence. J. Am. Acad. Audiol. 16, 494-504. doi:10.3766/jaaa.16.7.9

Tallal, P., and Newcombe, F. (1978). Impairment of auditory perception and language comprehension in dysphasia. Brain Lang. 5, 13-34. doi:10.1016/ 0093-934X(78)90003-2

Tremblay, K., Kraus, N., Carrell, T. D., and McGee, T. (1997). Central auditory system plasticity: generalization to novel stimuli following listening training. J. Acoust. Soc. Am. 102, 3762-3773. doi:10.1121/1.420139

Tremblay, K., Kraus, N., McGee, T., Ponton, C., and Otis, B. (2001). Central auditory plasticity: changes in the N1-P2 complex after speech-sound training. Ear Hear. 22, 79-90. doi:10.1097/00003446-200104000-00001

Tremblay, K. L., and Kraus, N. (2002). Auditory training induces asymmetrical changes in cortical neural activity. J. Speech Lang. Hear. Res. 45, 564-572. doi:10. 1044/1092-4388(2002/045)

Weinberger, N. M. (2004). Specific long-term memory traces in primary auditory cortex. Nat. Rev. Neurosci. 5, 279-290. doi:10.1038/nrn1366

Welsh, L. W., Welsh, J. J., and Healy, M. P. (1985). Central presbycusis. Laryngoscope 95, 128-136. doi:10.1288/00005537-198502000-00002

Willott, J. F. (1991). Aging and the Auditory System: Anatomy, Physiology and Psychophysics. San Diego: Singular Press.

Yesavage, J. A., Brink, T. L., Rose, T. L., Lum, O., Huang, V., Adey, M., et al. (1983). Development and validation of a geriatric depression screening scale: a preliminary report. J. Psychiatr. Res. 17, 37-49. doi:10.1016/0022-3956(82) 90033-4

Conflict of Interest Statement: The authors declare that the research was conducted in the absence of any commercial or financial relationships that could be construed as a potential conflict of interest.

Copyright (C) 2015 Morais, Rocha-Muniz and Schochat. This is an open-access article distributed under the terms of the Creative Commons Attribution License (CC BY). The use, distribution or reproduction in other forums is permitted, provided the original author(s) or licensor are credited and that the original publication in this journal is cited, in accordance with accepted academic practice. No use, distribution or reproduction is permitted which does not comply with these terms. 